\title{
ANÁLISE DAS NORMAS VIGENTES PARA REGISTRO DE FITOTERÁPICOS VETERINÁRIOS NO BRASIL
}

\author{
BRUNO, Luciana de Oliveira ${ }^{1}$; \\ MARQUES, Luís Carlos ${ }^{2}$; \\ CARDOSO, Caroly Mendonça Zanella ${ }^{3}$.
}

Recebido: $11 / 03 / 2016$

Aceito: $28 / 09 / 2016$

${ }^{1}$ Médica veterinária, Programa de Pós-Graduação em Ciências da Saúde, Universidade Federal de São Paulo (UNIFESP); ${ }^{2}$ Farmacêutico, Professor, Doutor, Centro de Pós-graduação, Pesquisa e Extensão Oswaldo Cruz FOC - São Paulo; ${ }^{3}$ Farmacêutica Industrial, Professora, Mestra, Centro de Pós-graduação, Pesquisa e Extensão Oswaldo Cruz - FOC - São Paulo.

\section{RESUMO}

\begin{abstract}
A nalisou-se o mercado de fitoterápicos de uso veterinário no Brasil e as normas vigentes que lhe são aplicadas. O Ministério da Agricultura, Pecuária e Abastecimento é o principal órgão responsável pela fiscalização dos produtos e empresas dessa área. Porém as normas legais vigentes são antigas, inespecíficas, apresentam contradições e erros técnicos, são rígidas e não incorporam os conceitos facilitadores da tradicionalidade fitoterápica, conjunto de problemas que impacta fortemente na mínima presença de fitoterápicos industrializados e registrados no Brasil. Sugere-se uma revisão do marco regulatório fitoterápico veterinário brasileiro, adotando-se a experiência na área humana como referência, complementando-se e ajustando-se devidamente em vários aspectos para as características veterinárias.
\end{abstract}

Palavras-chave: Fitoterapia. Plantas medicinais. Medicamentos fitoterápicos. Regulamentos. Legislação veterinária. 


\section{INTRODUÇÃO}

O mercado brasileiro de produtos veterinários é composto por vários tipos de produtos que vão de medicamentos a rações, suplementos alimentares e mais recentemente tem surgido espaço para os fitoterápicos. Estes, por sua vez, são medicamentos obtidos com emprego exclusivo de matérias-primas ativas vegetais, não se considerando medicamento fitoterápico aquele que inclua em sua composição substâncias ativas isoladas, sintéticas ou naturais, nem as associações dessas com extratos vegetais (BRASIL, 2014).

Dentre os produtos para uso veterinário encontramos os produtos alimentares, os produtos complementares para tratamento e desenvolvimento saudável dos animais, produtos de embelezamento e produtos com valor de medicamentos (naturais, sintéticos, homeopáticos e fitoterápicos).

O mercado de produtos veterinários tem a grande vantagem de oferecer uma diversidade de produtos para várias funções e aplicações práticas, tanto para grandes animais (equídeos, ruminantes, aves de produção e suínos) quanto para pequenos animais (seguimento Pet, que é representado pelos caninos, felinos, aves ornamentais, roedores e alguns animais exóticos, por exemplo, répteis etc.). E tem prosperado fortemente nos últimos anos, devido ao aumento do número de animais domésticos e ainda do rebanho nacional, com a venda de alimentos, insumos e medicamentos. Desses, o que apresenta maior evolução é o mercado Pet, pois cada vez mais pessoas estão adquirindo animais de estimação, e, consequentemente, ocorre o aumento da procura de produtos voltados para estética, saúde e alimentação de qualidade para seus pets (CAPANEMA et al., 2007; SILVA, 2011).

De acordo com pesquisas realizadas nos últimos anos, o Brasil tem sido considerado uma das maiores potências mundiais no que diz respeito à criação animal. Segundo dados de 2011, o IBGE (Instituto Brasileiro de Geografia e Estatística) demostrou que o País tem o maior rebanho bovino comercial do mundo, ultrapassando a marca de 212,8 milhões de cabeças. Mantém-se, também, como o quarto maior produtor de carne suína, com 34,9 milhões de animais abatidos, produzindo mais de 3,4 milhões de toneladas e representando $10 \%$ das exportações mundiais, além do grande aumento da cultura de aves, ovinos, equinos e outros (IBGE, 2011). Além disso, o mercado brasileiro de animais de companhia é o segundo maior 
do mundo com uma população de 52,2 milhões de cães e 22,1 milhões de gatos, à sua frente segue apenas os Estados Unidos (ABINPET, 2016). Em relação ao faturamento de produtos que compõe o mercado pet mundial, em 2014 o Brasil ocupou o 20 lugar com 7,3\% de participação, atrás dos Estados Unidos (30,9\%), ficando na sequência o Reino Unido (7\%), a França $(5,8 \%)$ e a Alemanha $(5,7 \%)$ (ABINPET, 2014$)$.

O mercado farmacêutico veterinário mundial apresentou um faturamento na ordem de US\$ 22,5 bilhões em 2012, com crescimento médio de 8\% a.a. desde 2002 (IFAH, 2014). Desse total, o mercado brasileiro em 2012 faturou 3,7 bilhões de reais (US\$ 1,95 bilhões), o que representou $8,7 \%$ do faturamento global (BNDES, 2013), valor bastante expressivo, principalmente em função do nosso numeroso rebanho bovino e do expressivo contingente de cães e gatos (SINDAN, 2015). A distribuição desse faturamento por classes de produtos está expressa na Figura 1.

\section{Classes de produtos (\%)}

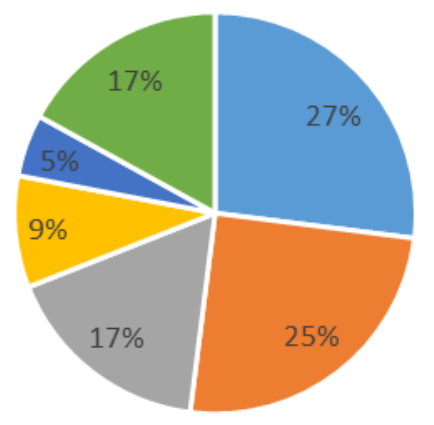

- Biológicos - Antiparasitários | Antimicrobianos " Terapêuticos Suplementos - Outros

Figura 1 - Participação dos produtos veterinários, separados por classes, no faturamento do mercado farmacêutico veterinário brasileiro no ano de 2012. Fonte: SINDAN.

A participação das categorias animais, no ano 2012, no faturamento do mercado farmacêutico veterinário brasileiro está demostrada na Figura 2. 


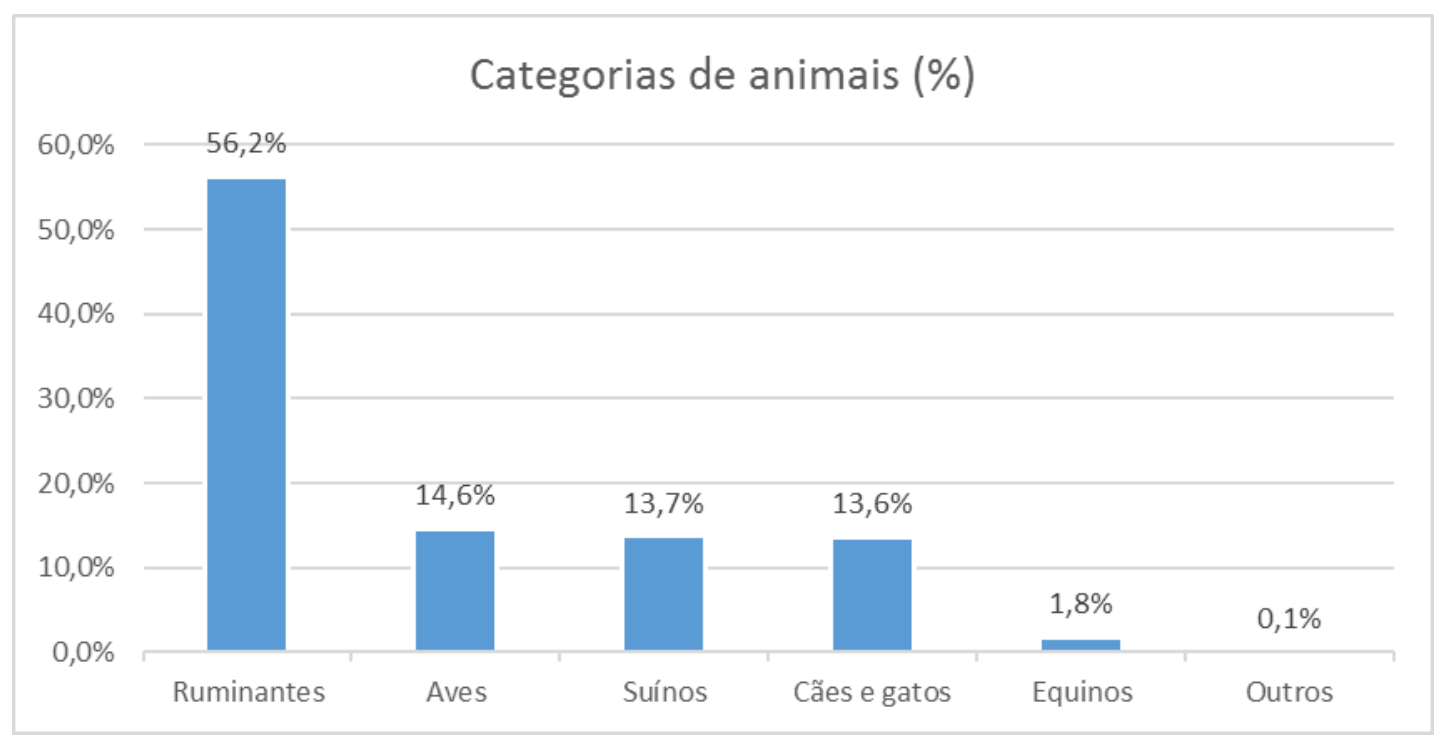

Figura 2 - Participação dos animais, separados por categorias, no faturamento do mercado farmacêutico veterinário brasileiro no ano de 2012. Fonte: SINDAN.

Em relação aos medicamentos veterinários da classe de fitoterápicos não há informações disponíveis, tanto em sites de entidades ou de empresas nacionais. Isso deve significar que, por questões diversas, a fitoterapia ainda não se expandiu significativamente na área veterinária.

O número de pessoas e profissionais que vem aderindo à fitoterapia é expressivo atualmente, interesse que se reflete no consumo de medicamentos fitoterápicos no Brasil. Consequentemente, isso aumenta também o interesse de maior investimento em Pesquisa e Desenvolvimento (P\&D) nesta área, já que o mercado veterinário é fortemente influenciado pelos proprietários dos animais.

Para atender a essa demanda, as empresas precisam desenvolver novos medicamentos e, para isso, precisam de um marco regulatório com orientação de como proceder. O marco regulatório de fitoterápicos no Brasil está bem estabelecido na área humana, sendo gerenciado pela Agência Nacional de Vigilância Sanitária (ANVISA), ligada ao Ministério da Saúde. Desde 1995, uma série de normas e procedimentos vem sendo editados, organizando e desenvolvendo o setor de fitoterápicos para saúde humana no País (CARVALHO et al., 2008). Adicionalmente, em 2006, foi editado o Decreto no 5813 que instituiu a Política Nacional de Plantas Medicinais e Fitoterápicos, com uma série de propostas para ampliação 
e desenvolvimento dessa terapêutica em vários níveis, buscando aumentar o aproveitamento da biodiversidade brasileira, estimular a indústria farmacêutica, inclusive do setor veterinário, gerar renda por cadeias produtivas, dentre várias outras propostas (BRASIL, 2006).

Na área veterinária, a regulação está a cargo do Ministério da Agricultura, Pecuária e Abastecimento (MAPA), que possui a atribuição legal para regulamentar a produção de produtos veterinários, inclusive os de origem vegetal. No entanto, diferentemente do que ocorreu na área humana, existem poucas normas sobre fitoterápicos veterinários e dúvidas sobre sua aplicação e efetividade.

Para o País, essa questão da utilização de plantas e seus princípios ativos para a produção de fitoterápicos e fitofármacos é especialmente importante, uma vez que o Brasil detém a maior parcela da biodiversidade mundial, em torno de 15 a $20 \%$ do total, com destaque para as plantas superiores, as quais representam aproximadamente $24 \%$ da biodiversidade. As plantas são, dentre os elementos que compõem a biodiversidade, a matéria prima central para a fabricação de fitoterápicos e outros medicamentos, já que cerca de $50 \%$ dos medicamentos são provenientes direta ou indiretamente de produtos naturais, principalmente das plantas medicinais (CARVALHO et al., 2007).

Nesse contexto, este trabalho objetivou avaliar o conteúdo das normas legais referentes a medicamentos fitoterápicos no Brasil, particularmente na área veterinária, buscando dessa forma contribuir à sua efetiva adequação e melhoria.

\section{METODOLOGIA}

Trata-se de uma revisão e análise crítica de literatura sobre a legislação vigente que se refere a regulamentação do registro de produtos fitoterápicos de uso veterinário que estão ou irão entrar no mercado brasileiro. Foram selecionadas referências disponíveis na biblioteca virtual BIREME, na biblioteca virtual SCIELO e no acervo bibliográfico da biblioteca virtual dos órgãos regulamentadores e fiscalizadores, a ANVISA e o MAPA. E conforme exigido, os unitermos escolhidos constam dos "Descritores em Ciências de Saúde" da Bireme (http://decs.bvs.br/). 


\section{NORMAS LEGAIS VIGENTES PARA REGISTRO DE FITOTERÁPICOS VETERINÁRIOS}

Pela edição do Decreto-lei no 467 de 13 de fevereiro de 1969 foi estabelecida a obrigatoriedade da fiscalização da indústria, do comércio e do emprego de produtos de uso veterinário, em todo território nacional, entendidos todos os preparados de natureza química, farmacêutica, biológica ou mista, com propriedades definidas e destinadas a prevenir, diagnosticar ou curar doenças dos animais, ou que possam contribuir para a manutenção da higiene animal. Tais produtos, nos quais se classificam também os fitoterápicos, ficam obrigados ao registro no órgão regulador federal (BRASIL, 1969).

O principal marco regulatório para os produtos de uso veterinário é o Decreto no 5053 de 22 de abril de 2004 que aprovou o regulamento de fiscalização de produtos de uso veterinário e dos estabelecimentos que os fabriquem ou comerciem e dá outras providências. Já o Decreto no 6296 de 11 de dezembro de 2007 e o Decreto no 8448 de 06 de maio de 2015 promovem algumas alterações e atualizam pontualmente o Decreto № 5053 (BRASIL, 2004; 2007; 2015).

De acordo com o Art. 24ํ do Decreto no 5053 (BRASIL, 2004), o produto de uso veterinário, produzido no País ou importado, para efeito de licenciamento, deverá ser registrado no MAPA. Essa norma estabelece, também, que compete ao MAPA baixar normas complementares aos temas relacionados a produtos veterinários. O requerimento da solicitação de registro do produto veterinário deverá ser feito junto à Secretaria de Defesa Agropecuária (SDA) do MAPA, devendo estar acompanhado de relatório descritivo específico para cada tipo ou natureza de produto, conforme descrito na Portaria SDA no 74 de 11 de junho de 1996 (BRASIL, 1996b).

A primeira norma específica em relação aos fitoterápicos para uso veterinário foi a Instrução de Serviços no 001/CPV de 29 de novembro de 2001, da Coordenação de Fiscalização de Produtos Veterinários (CPV) do MAPA, que disciplinou o uso de fitoterápicos e homeopáticos de uso veterinário (BRASIL, 2001; MAGALHÃES, 2016). Todas as outras normas não fazem referência a essa classe de produtos.

A IS 001/CPV/2001 estabeleceu orientações aos produtores, definiu a responsabilidade técnica tanto do médico veterinário quanto do farmacêutico, e, em relação a produtos, 
definiu genericamente que todos os procedimentos para registro de produtos fitoterápicos serão os mesmos aplicados aos produtos farmacêuticos, e, ainda, que a CPV deveria analisar a solicitação de registro e emitir licença provisória de um ano até a definição de legislação específica. Apesar da IS ter sido emitida em 2001, até o momento presente, não houve a edição de legislação específica sobre essa classe de produtos, aplicando-se aos fitoterápicos todas as exigências para produtos farmacêuticos em geral (BRASIL, 2001; MAGALHÃES, 2016; MAPA, 2016).

No caso de registro de fitoterápicos, seguindo as normas de produtos farmacêuticos, como mencionado anteriormente, a documentação deve estar de acordo com o roteiro aprovado pelo MAPA segundo a Portaria no 301 de 19 de abril de 1996 (BRASIL, 1996a).

O órgão responsável pela análise da solicitação de registro e emissão da licença provisória (de duração de 1 ano até definição de legislação específica) é a Coordenação de Fiscalização de Produtos de Uso Veterinário (CPV). Após a aprovação do produto, o Sindicato Nacional da Indústria de Produtos para Saúde Animal (SINDAN) com o apoio da CPV, órgão pertencente ao Departamento de Fiscalização de Insumos Pecuários (DFIP), que por sua vez integra a Secretaria de Defesa Agropecuária (SDA) do MAPA, disponibiliza para o setor veterinário o Compêndio de Produtos Veterinários, onde tanto as empresas associadas ou não colocam seus produtos de linha, facilitando a consulta dos dados das rotulagens e seu registro no MAPA.

Com essa edição eletrônica do Compêndio de Produtos Veterinários, os profissionais envolvidos com o setor, como médicos veterinários, ficarão ainda mais informados sobre novos produtos, ampliando as opções para prescrição, recomendação ou uso na profilaxia, controle e tratamento das enfermidades, bem como no incremento da produção e produtividade animal, pois a atualização do Compêndio é realizada de forma constante pelas próprias empresas e revisada pelo SINDAN, mediante confronto com as rotulagens aprovadas pelo MAPA (SINDAN, 2015).

\section{DAS BOAS PRÁTICAS DE FABRICAÇÃO}

Conforme a legislação brasileira, os medicamentos fitoterápicos podem ser manipulados ou industrializados. Podem, ainda, ser destinados ao uso humano ou veterinário, sendo os de 
uso humano regulamentados pela ANVISA e os produtos veterinários regulamentados pelo MAPA.

As exigências da ANVISA, em relação aos medicamentos para uso humano, aumentaram a qualidade dos produtos no mercado brasileiro e a confiança do consumidor. As regras para produção e registro de medicamentos fitoterápicos procuram garantir o mesmo efeito que um medicamento sintético. Atualmente, as normas vigentes são a Resolução RDC no 26 de 13 de maio de 2014, a Instrução Normativa № 02 de 13 de maio de 2014 e o Manual de Boas Práticas de Fabricação, conforme RDC no 17 de 16 de abril de 2010 (ANVISA, 2015).

Como não existem normas específicas para a industrialização de produtos fitoterápicos veterinários, se o produto em questão tiver a finalidade de ação profilática ou terapêutica, este deverá seguir todas as normas de boas práticas de fabricação para qualquer medicamento, conforme Instrução Normativa MAPA no 13 de 03 de outubro de 2003 (MAPA, 2012). Nesse aspecto, salvo um ou outro detalhe técnico específico, as boas práticas farmacêuticas são de fato aplicáveis à classe de fitoterápicos, considerando-se os controles, procedimentos operacionais padrão, limpeza, registro de etapas, etc.

\section{DO CONTROLE DE QUALIDADE}

\section{Matéria prima}

Para a matéria-prima vegetal é realizada a confirmação da identidade botânica, sua integridade, caracteres organolépticos, teor de umidade, presença de materiais estranhos como: partes indesejáveis da planta, material inorgânico e insetos, teor de cinzas, contaminantes tanto microscópicos quanto macroscópicos, incluindo fungos e bactérias, micotoxinas e metais pesados. Deve ser ainda informado o local de coleta e se foram utilizados métodos para eliminação de contaminantes, acompanhados da pesquisa de possíveis alterações dos ativos após a intervenção, bem como de resíduos relacionados ao método. E, finalmente, deve ser apresentada a análise qualitativa e quantitativa dos marcadores. O controle quantitativo de marcadores pode ser substituído por controle biológico da atividade terapêutica, embora este aspecto ainda seja alvo de polêmica, mesmo na área humana, por sua grande variabilidade. Os resultados para a droga vegetal só precisam ser apresentados quando a empresa fabricante do medicamento fitoterápico for 
também produtora do derivado vegetal, ou quando a droga vegetal for empregada como ativo no medicamento fitoterápico (ANVISA, 2015).

$\mathrm{Na}$ área do MAPA, os aspectos de controle de qualidade foram inicialmente estabelecidos pela Portaria no 301 de 19 de abril de 1996 (BRASIL, 1996a), juntamente com as exigências de produção. No entanto, alguns requisitos são tecnicamente confusos, como por exemplo, o citado no artigo 21, onde se define a necessidade de provar a pureza biológica (teste de esterilidade, pirogênio, toxicidade, contagem de micro-organismos viáveis e pesquisa e identificação de patógenos) a cada partida produzida, de acordo com a forma farmacêutica. Exigência necessária aos produtos injetáveis (teste de esterilidade) mas não aplicável a todas as formas farmacêuticas.

Ainda nesse mesmo artigo, cita-se exigência de controle de toxicidade, com apresentação de dados de testes diversos (carcinogênico, teratogênico, mutagênico, discrasia sanguínea, neurotoxicidade, hipersensibilidade, efeitos sobre a reprodução e sobre flora normal). Essa exigência é tecnicamente pouco adequada, pois são testes feitos durante o desenvolvimento dos estudos prévios ao registro e apresentados apenas uma única vez, e não precisam ser repetidos a cada lote ou partida.

Desse modo, as exigências nesse item são amplas, rígidas e confusas, levando à conclusão de que realmente se faz necessário um marco regulatório atual e mais pertinente.

\section{Derivados vegetais (extratos)}

Em relação aos derivados vegetais, como não existem normas específicas determinadas pelo MAPA, as normas da ANVISA, sobre esse tema, são utilizadas como alternativa (ANVISA, 2015).

Assim, devem ser observados, no derivado vegetal, quais métodos de extração foram empregados e testes para verificação da presença de resíduos de solventes orgânicos. Testes físico-químicos do extrato são, também, exigidos e incluem: resíduo seco, caracterização organoléptica, $\mathrm{pH}$, teor alcoólico densidade (para extratos líquidos); umidade/perda por dessecação, solubilidade e densidade aparente (para extratos secos); densidade, índice de 
refração, rotação óptica (para óleos essenciais); e índice de acidez, de éster, de iodo (para óleos fixos).

Deve-se incluir nos documentos de registro um laudo do fornecedor da matéria-prima, considerando que não serão dadas as informações da droga vegetal. Neste laudo deverão estar descritas as seguintes informações: nomenclatura botânica completa e atualizada; parte da planta utilizada; solventes, excipientes e/ou veículos utilizados na extração do derivado; relação aproximada da droga vegetal: derivado vegetal; e a descrição do método para eliminação de contaminantes, quando utilizado, e a pesquisa de eventuais alterações.

Todas as metodologias analíticas empregadas devem ser oficialmente reconhecidas no País, por meio da Farmacopeia Brasileira ou equivalentes internacionais, ou validadas conforme o disposto na Resolução RE no 899 de 29 de maio de 2003 (ANVISA, 2015).

A legislação admite que as metodologias farmacopeicas não precisam ser validadas, sendo consideradas metodologias farmacopeicas as que estão presentes na Farmacopeia Brasileira e nas últimas edições das Farmacopeias oficializadas no País, que são, atualmente: Farmacopeia Alemã, Farmacopeia Americana, Farmacopeia Argentina, Farmacopeia Britânica, Farmacopeia Europeia, Farmacopeia Francesa, Farmacopeia Internacional (OMS), Farmacopeia Japonesa, Farmacopeia Mexicana, Farmacopeia Portuguesa, conforme estabelecido na RDC no 37 de 06 de julho de 2009 (ANVISA, 2015).

A Farmacopeia Brasileira passou por um processo de revisão, em parceria com universidades brasileiras, passando a vigorar em 2010, com a publicação da 5a edição dividida em 2 volumes (ANVISA, 2015; BRASIL, 2010).

\section{Produto acabado}

Do produto final, de acordo com a sua forma farmacêutica, o controle pode variar. Mas se faz imprescindível a avaliação da integridade e da estabilidade do produto (inclusive pela dosagem de marcadores), além do controle dos níveis de contaminação microbiana.

Se o derivado utilizado no produto final tiver sido extraído da planta com o mesmo solvente utilizado na metodologia farmacopeica e não possua adição de excipientes, não é necessária a apresentação de nova validação da metodologia analítica. Uma alteração na obtenção do 
extrato, principalmente em relação ao solvente utilizado, leva a uma composição diferente do extrato e será considerado como uma mudança na composição do produto acabado, ensejando uma revalidação da metodologia analítica conforme item 1.12.2 da Resolução RE no 899 de 29 de maio de 2003. Esses parâmetros que serão revalidados, de forma geral, são especificidade, exatidão e precisão e dependem principalmente da alteração realizada no processo (ANVISA, 2015; BRASIL, 2010).

Novamente, pela falta de normas específicas do MAPA, se recomendam as orientações da ANVISA, denotando novamente a necessidade de atualização das normas da área veterinária para fitoterápicos.

\section{Dos aspectos de segurança}

$\mathrm{Na}$ área humana, a RDC no 26 de 13 de maio de 2014 prevê variadas formas de avaliar e comprovar a segurança e eficácia terapêutica dos fitoterápicos (ANVISA, 2015). Dentre elas podemos citar a possibilidade do uso de informações disponibilizadas sobre o tradicional uso de plantas e suas respectivas indicações. Isso indica que, a empresa solicitante deverá apresentar levantamento bibliográfico aprofundado (de documentações técnico-científicas ou publicações, além de apresentarem informações sobre a etnofarmacologia e suas utilizações) que será avaliado criteriosamente de acordo com: indicação de uso para curtos períodos de uso ou episódicos; coerência com as suas indicações terapêuticas propostas; ausência de toxicidade; ausência de grupos de substâncias químicas tóxicas ou presentes comprovadamente dentro de limites seguros de uso; e comprovação de uso seguro por período igual ou superior a 20 anos de uso (CARVALHO et al., 2007). Além desta RDC, existe outra norma complementar e de orientações quanto ao registro de fitoterápicos que é a Resolução RE no 90 de 16 de março de 2004 onde está descrito o Guia para a Realização de Estudos de Toxicidade Pré-clínica de Fitoterápico (ANVISA, 2015). Esse guia deve ser utilizado no caso de espécies nas quais não for possível comprovar segurança por tradicionalidade, devendo ser realizado apenas uma vez e apresentado por ocasião do pedido de registro. Esses testes de toxicidade têm a finalidade de determinar os efeitos nocivos da droga no organismo do animal, em especial, nos sistemas cardiovascular, 
reprodutor, hepático e renal, bem como as alterações genéticas (ARAUJO, 2013; PIERONI et al., 2009).

As exigências de segurança na área veterinária estão detalhadas na Portaria SDA no 74 de 11 de junho de 1996 (BRASIL, 1996b). Apesar de não haverem citações referentes a fitoterápicos, mas considerando-se o item de produtos biológicos, a norma exige, em todas as partidas, a série de testes já citados anteriormente, entretanto fica em aberto a possibilidade de serem atendidos por trabalhos referenciados na bibliografia. Portanto, como sugestão a este item, o esquema adotado na área humana é bem cabível, isto é, necessita-se de um roteiro para testes de toxicidade durante o desenvolvimento, a ser apresentado exclusivamente no registro, bem como, deve-se aceitar os levantamentos bibliográficos que indiquem tradicionalidade, condição que liberaria o estudo próprio após avaliação dos dados apresentados.

\section{Da eficácia terapêutica}

Os testes de eficácia têm como objetivo principal determinar a absorção, distribuição, metabolização e excreção do novo composto, bem como seus efeitos terapêuticos provados em modelos in vitro, in vivo e em ensaios clínicos (ARAUJO, 2013; PIERONI et al., 2009).

Na área veterinária, este tema é tratado pela Portaria SDA no 74 de 11 de junho de 1996, que no Roteiro para Registro de Produtos Farmacêuticos de Uso Veterinário, Descrição do Produto, item 10.2, diz: "Descrição das provas de eficácia biológica e ou farmacológica, de acordo com o inciso II do Art. 21 das Normas aprovadas pela Portaria Ministerial no 301, de 19/04/96" (BRASIL, 1996b). Curiosamente, ao buscar-se o conteúdo indicado na outra norma, encontram-se as exigências, já referidas anteriormente, sobre provas de pureza biológica (teste de esterilidade, pirogênio, toxicidade, contagem de microrganismos viáveis e pesquisa de identificação de patógenos) por partida produzida. Portanto, não havendo qualquer relação entre essas duas exigências, demonstrando novamente a defasagem do marco regulatório da área farmacêutica veterinária brasileira.

Como recomendação, poder-se-ia usar as orientações gerais das normas da área humana, com as adaptações necessárias. Desse modo, sugere-se um roteiro básico, composto das seguintes etapas: 
a) Etapa bibliográfica

Desenvolver ou obter referências em livros textos, estudos farmacológicos publicados, resumos de congressos, evidências do uso tradicional, etc. De posse desses dados, definir se o produto tem perfil completo ou parcial de tradicionalidade, ou deve ser considerado novo, isto é, não previamente utilizado popularmente, necessitando, portanto, de uma avaliação completa, integral.

b) Parâmetros adicionais

Complementar a análise anterior (tradicional ou novo) com avaliação da presença de classes químicas de risco, como alcaloides, cianogênicos ou cardiotônicos, as quais, se presentes, deslocariam a espécie para a categoria de novo, tendo em vista os riscos associados. Avaliar, também, se as indicações são preventivas ou paliativas, típicas dos produtos tradicionais, ou para quadros e patologias mais graves, condição de produto de classificação como novo.

c) Estabelecimento de níveis de exigências conforme informações das etapas anteriores, tais como citados na Figura 3.

\begin{tabular}{|lll|}
\hline $\begin{array}{l}\text { Proposta } \\
\text { de níveis }\end{array}$ & Características do produto & Exigências \\
\hline Nível 1 & $\begin{array}{l}\text { Produto tradicional, com estudos, sem classes } \\
\text { químicas de risco, sintomático. }\end{array}$ & Sem exigências adicionais. \\
& Produto tradicional, com estudos, com classes & \\
& químicas de risco, sintomático ou para & Com exigências adicionais, \\
Nível 2 & patologias graves. & \\
& Novo, sem estudos, com ou sem classes & \\
& químicas de risco, sintomático ou para & Com exigências totais, tanto \\
Nível 3 & patologias graves. & em segurança quanto eficácia. \\
& &
\end{tabular}

Figura 3 - Proposta de organização das exigências de segurança e eficácia para fitoterápicos veterinários segundo informações de tradicionalidade ou novo. 
De acordo com o maior nível, maiores exigências de estudos com animais (clínico veterinário) serão estabelecidas.

A Portaria SDA no 74 de 11 de junho de 1996, em seu item "Roteiro para Registro de Produtos Farmacêuticos de Uso Veterinário", refere para os produtos uma série de outras exigências como: dose, duração de tratamento, margem de segurança, etc., as quais são usuais para medicamentos e plenamente cabíveis para os fitoterápicos. No entanto, há alguns itens inaplicáveis a produtos fitoterápicos, como dados farmacocinéticos (vias de absorção, distribuição e eliminação dos princípios ativos e/ou seus metabólitos) ou controle sobre resíduos medicamentosos (limite máximo de resíduos nos tecidos, leite, ovos e mel) (BRASIL, 1996b). Isso decorre do fato de existirem nas plantas e, portanto, nos extratos e produtos fitoterápicos finais, um conjunto enorme de ativos denominado genericamente de "fitocomplexo". Muitos desses ingredientes são encontrados em doses muito baixas, o que inviabiliza sua medição em líquidos biológicos ou tecidos, como é usual em medicamentos sintéticos. Assim, não há informação clara sobre a farmacocinética e nem é possível, na grande maioria dos casos, avaliar se o medicamento fitoterápico está ainda presente no leite, carne ou ovos, inclusive por que em muitos casos não se conhece exatamente nem qual é o alvo químico adequado para essa medicação (ANVISA, 2015; BRASIL, 1996b).

Assim, estes dois itens não devem ser mantidos por ocasião da edição de normas fitoterápicas veterinárias no Brasil.

\section{CONSIDERAÇÕES FINAIS}

A falta de um marco regulatório desenvolvido especificamente para os produtos fitoterápicos veterinários faz com que as empresas ou não desenvolvam produtos nessa categoria ou sofram análises inadequadas pelos técnicos do MAPA, situação refletida pelo baixíssimo número de fitoterápicos veterinários registrados e comercializados no Brasil. Essa falta de definição inibe os investimentos de pequenos e médios laboratórios brasileiros que concorrem no setor.

A existência de um marco regulatório específico, adequado a realidade econômica, tecnológica e de P\&D do País, que detém grande parcela da biodiversidade mundial, aliado a uma política industrial e tecnológica desenvolvida exclusivamente para o setor, que ofereça 
instrumentos que reforcem a promoção comercial e o crédito, permitiriam a exploração racional desse mercado, garantindo a segurança e a eficácia dos fitoterápicos veterinários produzidos no Brasil além de valorizar e estimular a pesquisa sobre plantas medicinais nativas.

\section{CONCLUSÃO}

A análise dos dados e das observações apresentadas neste trabalho permitem concluir que o marco regulatório veterinário brasileiro em relação aos produtos fitoterápicos veterinários mostra-se aquém das necessidades atuais desse nicho de mercado, pois utiliza de modo provisório as normas gerais que regulamentam os medicamentos de uso veterinário, muitas vezes imprecisas, inaplicáveis ou ausentes para esse tipo de produto.

As normas atuais, amplas, genéricas, algumas vezes contraditórias, constituem em empecilho regulatório significativo, por isso, sugere-se uma revisão do marco regulatório fitoterápico veterinário brasileiro, adotando-se a experiência na área humana como referência, complementando e ajustando devidamente os vários aspectos às peculiaridades do mercado de produtos farmacêuticos veterinários.

\section{REVIEW OF THE CURRENT GUIDELINES FOR THE REGISTRATION OF VETERINARY PHYTOMEDICINES IN BRAZIL}

\section{ABSTRACT}

$\mathrm{T}$ his study analyzed the market of herbal medicines for veterinary use in Brazil and the standards applied. The Ministry of Agriculture, Livestock and Supply is the main agency responsible for the inspection of products and companies in this area. However, the prevailing legal guidelines are old, nonspecific and present contradictions and technical errors, they are also rigid and do not incorporate the facilitator concepts of herbal traditionalism. This set of problems strongly affects the little presence of industrialized and registered phytomedicines in Brazil. A review of the Brazilian regulatory framework, complementing and adjusting the references of the human area for phytomedicines of veterinary use is suggested.

Keywords: Phytotherapy. Herbal drugs. Phytotherapeutic drugs. Regulations. Veterinary legislation. 


\section{REVISIÓN DE LAS NORMAS ACTUALES DE LOS FITOMEDICAMENTOS VETERINÁRIOS EN BRASIL}

\section{RESUMEN}

S

e analizó el mercado de los fitoterapéuticos para uso veterinario en Brasil y las normas que se aplican sobre el registro de estos productos antes de que entren al mercado. El Ministerio de Agricultura, Ganadería y Abastecimiento es la principal autoridad responsable de hacer la inspección de los productos y las empresas en este ámbito. Pero las normas legales vigentes son antiguas, inespecíficas, contradictorias y presentan errores técnicos, son demasiado rígidas y no incorporan los conceptos tradicionales de las drogas fitoterapéuticas, factores que causan un fuerte impacto en la presencia de estas medicinas industrializadas e registradas en Brasil. Se aconseja una revisión del marco regulatorio fitoterapéutico veterinario brasilero, teniendo como referencia la experiencia en el área humana, pero complementándola y adaptándola debidamente a las características veterinarias.

Palabras clave: Fitoterapia. Preparaciones de plantas. Medicina de hierbas. Normativas. Legislación veterinaria.

\section{REFERÊNCIAS}

ABINPET - ASSOCIAÇÃO BRASILEIRA DA INDÚSTRIA DE PRODUTOS PARA ANIMAIS DE ESTIMAÇÃO. Sobre a Desenvolve SP - Agência de Desenvolvimento Paulista. Mercado segue em desenvolvimento e mantém segundo lugar no ranking mundial. Disponível em: <http://abinpet.org.br>. Acesso em: novembro de 2014.

ABINPET - ASSOCIAÇÃO BRASILEIRA DA INDÚSTRIA DE PRODUTOS PARA ANIMAIS DE ESTIMAÇÃO. Dados de Mercado. Disponível em: <http://abinpet.org.br/site/>. Acesso em: agosto 2016.

ANVISA - AGÊNCIA NACIONAL DE VIGILÂNCIA SANITÁRIA. Consolidado de normas da Coordenação de Medicamentos Fitoterápicos e Dinamizados - COFID (Versão V). Brasília, 2015. Disponível em:

<http://portal.anvisa.gov.br/documents/33836/351731/Consolidado\%2BCOFID\%2BV.pdf/c0 aa90e3-f884-4554-92bb-4a339f5be202>. Acesso em: julho de 2016.

ARAUJO, S. G. Perspectivas e desafios para o desenvolvimento de fitoterápicos com plantas medicinais da Mata Atlântica para uso veterinário. Rio de Janeiro: FIOCRUZ, 2013. 149p. Monografia (Especialização em Gestão da Inovação em Fitomedicamentos). Centro Tecnológico de Medicamentos, Farmanguinhos, Fundação Oswaldo Cruz, 2013. 
BNDES - BANCO NACIONAL DE DESENVOLVIMENTO ECONÔMICO E SOCIAL. A evolução recente da indústria farmacêutica veterinária brasileira. Informe Setorial, área industrial, $n$. 27, p. 1-5, nov. 2013. Disponível em:

<http://www.bndes.gov.br/SiteBNDES/export/sites/default/bndes_pt/Galerias/Arquivos/co nhecimento/setorial/Informe_27.pdf>.

BRASIL. Decreto-lei no 467 de 13 de fevereiro de 1969. Estabelece a obrigatoriedade da fiscalização da indústria, do comércio e do emprego de produtos de uso veterinário, em todo o território nacional. In: Diário Oficial da União, Brasília, 14 de fevereiro de 1969.

BRASIL. Ministério da Agricultura, do Abastecimento e da Reforma Agrária. Portaria no 301 de 19 de abril de 1996. Aprova normas complementares a serem observadas pelos estabelecimentos que fabriquem e ou comerciem produtos de uso veterinário. Diário Oficial da União, Brasília, seção 1, n. 80, p. 7013 de 25 de abril de 1996a.

BRASIL. Ministério da Agricultura e do Abastecimento. Portaria SDA no 74 de 11 de junho de 1996. Aprova os roteiros para elaboração de relatórios técnicos visando o registro de produtos: biológicos, farmacêuticos, farmoquímicos e de higiene e/ou embelezamento de uso veterinário. In: Diário Oficial da União, Brasília, seção 1, n. 117, p. 10818, 19 de junho de $1996 b$.

BRASIL. Ministério da Agricultura, Pecuária e Abastecimento. Secretaria de Defesa Agropecuária. Coordenação de Fiscalização de Produtos Veterinários. Instrução de Serviço no 001 de $\mathbf{2 9}$ de novembro de 2001. Disciplina o uso de produtos fitoterápicos e homeopáticos de uso veterinário, Brasília, 2001. Disponível em: <file:///C:/Users/pricc/Downloads/ISV00000001.pdf>. Acesso em: agosto 2016.

BRASIL. Decreto no 5053 de 22 de abril de 2004. Aprova o regulamento de fiscalização de produtos de uso veterinário e dos estabelecimentos que os fabriquem ou comerciem e dá outras providências. In: Diário Oficial da União, Brasília, seção 1, n. 77, p. 1, 23 de abril de 2004.

BRASIL. Decreto no 5813 de 22 de junho de 2006. Aprova a política nacional de plantas medicinais e fitoterápicos e dá outras providências. In: Diário Oficial da União, Brasília, seção 1, n. 119, p. 2, 23 de junho de 2006.

BRASIL. Decreto no 6296 de 11 de dezembro de 2007. Aprova o regulamento da Lei no 6198, de 26 de dezembro de 1974, que dispõe sobre a inspeção e a fiscalização obrigatórias dos produtos destinados à alimentação animal, dá nova redação aos arts. 25 e 56 do Anexo ao Decreto no 5053, de 22 de abril de 2004, e dá outras providências. In: Diário Oficial da União, Brasília, seção 1, n. 242, p. 1, 18 de dezembro de 2007.

BRASIL. Agência Nacional de Vigilância Sanitária. Farmacopeia Brasileira. 5. ed. 2010. Disponível em: <http://www.anvisa.gov.br/hotsite/cd_farmacopeia/index.htm>. Acesso em: janeiro de 2015. 
BRASIL. Agência Nacional de Vigilância Sanitária. Medicamentos Fitoterápicos. Disponível em: <http://www.anvisa.gov.br/medicamentos/fitoterapicos/definicao.htm>. Acesso em: novembro de 2014.

BRASIL. Decreto no 8448 de 06 de maio de 2015. Altera o regulamento de fiscalização de produtos de uso veterinário e dos estabelecimentos que os fabriquem ou comerciem, aprovado pelo Decreto no 5053, de 22 de abril de 2004. In: Diário Oficial da União, Brasília, seção 1, n. 85, p. 2, 07 de maio de 2015.

CAPANEMA, L. X. L.; VELASCO, L. O. M.; SOUZA, J. O. B.; NOGUTI, M. B. Panorama da Indústria Farmacêutica Veterinária. BNDES Setorial, Rio de Janeiro, v. 25, p. 157-174, 2007.

CARVALHO, A. C. B.; BALBINO, E. E.; MACIEL, A.; PERFEITO, J. P. S. Situação do registro de Medicamentos Fitoterápicos no Brasil. Revista Brasileira de Farmacognosia, v. 18, n. 2, p. 314-319, abr./jun. de 2008.

CARVALHO, A. C. B.; NUNES, D. S. G.; BARATELLI, T. G.; SHUQAIR, N. S. M. S. A. Q.; MACHADO NETTO, E. Aspectos da legislação no controle dos medicamentos fitoterápicos. T \& C Amazônia, v. 11, p. 26-32, 2007.

IBGE - INSTITUTO BRASILEIRO DE GEOGRAFIA E ESTATÍSTICA. Produção da Pecuária Municipal 2011, v. 39, p. 1-63, 2011. Disponível em:

<ftp://ftp.ibge.gov.br/Producao_Pecuaria/Producao_da_Pecuaria_Municipal/2011/ppm201 1.pdf>.

IFAH - INTERNATIONAL FEDERATION FOR ANIMAL HEALTH. Highlights Vital Role of Animal Health Industry in Maintaining Welfare on World Veterinary Day. Publicado em: 25 de abril de 2014. Disponível em: <http://healthforanimals.org/ifah-highlights-vital-role-of-animalhealth-industry-in-maintaining-welfare-on-world-veterinary-day/>. Acesso em: novembro de 2014.

MAGALHÃES, A. C. Fiscalização da produção e comércio de produtos veterinários e alimentos para animais. Slideplayer. FFA/SEFAG/SFA/RJ, slide 31. Disponível em: <slideplayer.com.br/slide/6611549/>. Acesso em: agosto 2016.

MAPA - MINISTÉRIO DA AGRICULTURA, PECUÁRIA E ABASTECIMENTO. Secretaria de Defesa Agropecuária. Departamento de Fiscalização de Insumos Pecuários. Legislação relacionada aos produtos de uso veterinário. Brasília: MAPA/ACS, 2012. 401p. Disponível em: $<$ www.cobea.org.br/arquivo/download?ID_ARQUIVO=41>. Acesso em: agosto de 2016.

MAPA - MINISTÉRIO DA AGRICULTURA, PECUÁRIA E ABASTECIMENTO. Secretaria de Defesa Agropecuária. Departamento de Fiscalização de Insumos Pecuários - DFIP. Coordenação de Fiscalização de Produtos de Uso Veterinário - CPV. Existe norma específica para produtos fitoterápicos? Disponível em: 
<http://www.agricultura.gov.br/arq_editor/file/Registros_Autorizacao/FAQ/Registro\%20de \%20Produtos\%20l_06.pdf>. Acesso em: 19 de agosto de 2016.

PIERONI, J. P.; CAPANEMA, L. X. L.; REIS, C.; SOUZA, J. O. B.; SILVA, L. G. Terceirização de P\&D de medicamentos: panorama do setor de testes pré-clínicos no Brasil. BNDES Setorial. Rio de Janeiro, n. 29, p. 131-158, 2009. Disponível em:

<http://www.bndes.gov.br/SiteBNDES/export/sites/default/bndes_pt/Galerias/Arquivos/co nhecimento/bnset/Set2904.pdf>. Acesso em: janeiro de 2015.

SILVA, P. Inovação em fitoterápicos: uma corrida de obstáculos para acesso a recursos genéticos. Revista Facto ABIFINA, n. 30, p. 11, jul./set. 2011. Disponível em:

$<$ http://www.abifina.org.br/revista_facto_materia.php?id=420>. Acesso em: janeiro de 2015.

SINDAN - SINDICATO NACIONAL DA INDÚSTRIA DE PRODUTOS PARA SAÚDE ANIMAL. Dados de mercado. Atualizado em 01/07/2015. Disponível em:

<http://www.sindan.org.br/sd/base.aspx?controle=8>. Acesso em: novembro de 2015.

Autor para correspondência: Luciana de Oliveira Bruno.

Programa de Pós-Graduação em Ciências da Saúde, Universidade Federal de São Paulo (UNIFESP) - São Paulo, Brasil. Ibrunovet@gmail.com 